\title{
A BIBLIOMETRIC STUDY ON STUDENTS' THESES AT THE DEPARTMENT OF ELEMENTARY SCHOOL TEACHER EDUCATION, UNIVERSITAS NEGERI MAKASSAR
}

\author{
Masni $^{1}$ \\ ${ }^{1}$ Mahasiswa Jurusan Ilmu Perpustakaan, Universitas Islam Negeri Alauddin \\ Correspondence email: masni990322@gmail.com
}

\begin{abstract}
Bibliometrics is a scientific study of which one of the benefits is predicting the development of a scientific discipline. This bibliometrics study is intended to find out what research themes and subjects are often used as thesis research topics for students of the Department of PGSD, Makassar State University. Bibliometrics research uses a statistical approach in measuring bibliography which in this case is a thesis. The population in this study is the title of student theses for the period 2017-2018 with a total sample of 338 thesis titles. Data collection techniques are done through documentation that is analyzed using a simple statistical formula. The results showed that subjects that were often used as research themes by PGSD majors were learning methods, namely 198 thesis titles with a percentage of $58.58 \%$ of the total sample. While for subjects that are often used as research objects are 114 Natural Sciences thesis titles with a percentage of $33.73 \%$ of the total sample.
\end{abstract}

Keywords: Bibliometrics; elementary school teacher education

\begin{abstract}
Abstrak
Bibliometrika merupakan kajian keilmuan yang salah satu manfaatnya ialah memprediksi perkembangan suatu disiplin ilmu. Kajian bibliometrika ini dimaksudkan untuk mengetahui tema penelitian dan subjek apa saja yang sering dijadikan sebagai topik penelitian skripsi mahasiswa Jurusan PGSD, Universitas Negeri Makassar. Penelitian bibliometrika menggunakan pendekatan statistika dalam mengukur bibliografi yang dalam hal ini ialah skripsi. Populasi dalam penelitian ini adalah judul skripsi mahasiswa periode tahun 2017-2018 dengan jumlah sampel sebanyak 338 judul skripsi. Teknik pengumpulan data dilakukan melalui dokumentasi yang dianalisis menggunakan rumus statistik sederhana. Hasil penelitian menunjukkan bahwa subjek yang sering dijadikan tema penelitian oleh mahasisiwa jurusan PGSD adalah Metode Pembelajaran yakni sebanyak 198 judul skripsi dengan persentase sebesar 58,58\% dari total keseluruhan sampel. Sementara untuk mata pelajaran yang sering dijadikan objek penelitian adalah mata pelajaran IPA sebanyak 114 judul skripsi dengan persentase sebesar 33,73\% dari total sampel.
\end{abstract}

Kata kunci: Bibliometrika; pendidikan guru sekolah dasar 


\section{Pendahuluan}

Berdasarkan Pedoman Umum Pengelolaan Koleksi Perpustakaan Perguruan Tinggi, bahwa untuk mengimbangi perkembangan penelitian yang dilakukan dalam lingkup perguruan tinggi, perpustakaan perguruan tinggi mempunyai tugas utama dalam penyediaan koleksi literatur ilmiah dan bahan koleksi lainnya yang di butuhkan oleh peneliti. Fungsi riset juga harus dimiliki oleh setiap perpustakaan perguruan tinggi, di mana fungsi ini bertujuan untuk mencari setiap bahan koleksi primer maupun sekunder sebagai bahan rujukan yang tepat untuk mencari informasi guna menyelesaikan penelitian dan pengkajian suatu ilmu pengetahuan dan teknologi. Oleh karena itu perpustakaan memiliki peran penting dalam proses pengolahan, penyajian dan penyimpanan sumber-sumber informasi yang bisa mendukung dalam kegiatan penelitian dan pengkajian.

Dalam hal ini kajian bibliometrika diperlukan guna mengetahui secara deskriptif dan jelas hasil penelitian yang dituangkan dalam bentuk skripsi mahasiswa pada bidang ilmu pendidikan. Menurut Kamus Bibliometrika, bibliomterika ialah "the application of mathematical and statistical techniques to the study of publishing and professional communication" (Diodato, 1994). Bibliometrik juga meliputi penjelasan mengenai perkembangan subjek, termasuk pada disiplin ilmu-ilmu sosial (Archambault \& Gagne, 2004) dan (Fattah, 2013). Pada penelitian bibliometrik mempunyai tujuan untuk mengetahui keberadaan universal mengenai produksi maupun perkembangan ilmu pengetahuan dengan menggunakan kajian tentang penulis, pengutipan, artikel dalam sebuah karya tulis ilmiah (Sulistyo-Basuki, 2002), (Esshra, 2007), (Nelisa, 2009), dan (Saleh, 2017).

Sebagai calon ilmuwan, mahasiswa juga perlu memahami kajian bibliometrik. Dalam sebuah penelitian yang disebut pemetaan ilmu telah dilakukan oleh seorang peneliti dimana penelitian tersebut mempunyai tujuan yang sama dengan kajian bibliometrik yaitu agar tidak mengalami kendala maupun kesulitan dalam memilih suatu topik pada saat melakukan penelitian suatu karya ilmiah. Di sisi lain, hambatan yang biasanya dihadapi oleh mahasiswa ketika telah menetukan topik penelitian adalah sumber referensi maupun tinjauan pustaka yang sulit di dapatkan terhadap topik penelitian yang sejenis dengan penelitiannya itu. Kondisi ini juga dialami oleh hampir semua mahasiswa jika tidak dilakukan kajian bibliometrika.

Berdasarkan peraturan perundang-undangan dalam hal ini terkait dengan kajian bibliometrik terdapat pada pasal 12 tentang koleksi perpustakaan ayat ke (2) yang menyatakan bahwa pengembangan koleksi perpustakaan sebagaimana di maksud pada ayat (1) dilakukan sesuai dengan standar nasional perpustakaan. Sebagaimana pada ayat (1) menjelaskan bahwa koleksi perpustakaan diseleksi, diolah, disimpan, dilayankan, dan dikembangkan sesuai dengan kepentingan pemustaka dengan memperhatikan perkembangan teknologi informasi dan komunikasi. Dimana pada pengembangan koleksi perpustakaan ditujukan sebagai pengembangan subjek 
dalam sebuah disiplin ilmu yang dimana sangat penting untuk dikaji melalui kajian bibliometric (UU Nomor 43 Tahun 2007 Tentang Perpustakaan).

Melalui kajian bibliometrik tersebut seseorang akan dapat secara cepat dan ringkas memperoleh suatu informasi atau data yang diperlukannya. Ada beberapa manfaat yang bisa diperoleh dengan pemetaan, diantaranya adalah: (1) memudahkan proses identifikasi permasalahan penelitian, (2) memperjelas gambaran penelitian yang ada di lapangan, (3) membantu dalam menetapkan kebijakan dan agenda aksi yang akan dilakukan peneliti. Dengan berbagai macam tema yang ada diatas akan mendorong perkembangan bidang Ilmu Informasi dan Perpustakaan.

Alasan peneliti juga memutuskan untuk meneliti di Fakultas Ilmu Pendidikan Jurusan PGSD Universitas Negeri Makassar adalah dalam hal akademik di karenakan masih banyak penelitian yang di kaji dengan subjek yang sama setiap tahunnya sehingga tidak ada perkembangan disiplin ilmu yang seharusnya menjadi acuan agar dapat membantu perkembangan berfikir setiap mahasiswa lebih kreatif dan berfikir kritis menganalisis masalah yang terdapat disekitar agar menjadi kajian penelitian yang bermanfaat bagi banyak orang.

\section{Metode}

Penelitian bibliometrika ini menggunakan statistik sederhana dalam mengukur skripsi-skripsi yang dihasilkan Jurusan PGSD UNM dari tahun 2017 hingga tahun 2018 yang berjumlah 2909 judul. Berdasarkan tabel Krejcie dan Morgan (taraf kepercayaan 90\%) (Krejcie \& Morgan, 1970), maka ditarik sampel dari keseluruhan skripsi tersebut menjadi 338 judul. Data diperolah melalui koleksi skrispi yang ada di Perpustakaan PGSD UNM. Untuk menampilkan data yang telah didapatkan, penulis akan menggunakan tabel frekuensi sederhana (Sugiyono, 2013) dengan menggunakan formula:

$P=\frac{F}{N} \times 100$

Keterangan:

$\mathrm{P}=$ angka persentase

$\mathrm{F}=$ Frekuensi

$\mathrm{N}=$ Jumlah keseluruhan skripsi

\section{Hasil Penelitian}

Sebagaimana yang disebutkan sebelumnya bahwa salah satu manfaat kajian bibliomterika ialah untuk mempelejari perkembangan suatu disiplin ilmu. Bagi perpustakaan, bibliometrika dapat digunakan sebagai dasar kebijakan untuk pengembangan koleksi atau bahan bacaan. Berikut ini akan ditunjukkan hasil penelitan.

Dari data sampel skripsi yang diperolah yaitu sebanyak 338 judul skripsi yang diambil secara acak terbit dari tahun 2017-2018, dapat digambarkan pada tabel di bawah ini. 
Tabel 1. Jumlah Skripsi Mahasiswa PGSD Tahun 2017-2018

\begin{tabular}{|l|c|c|c|}
\hline No & \multirow{2}{*}{ Tahun } & Jumlah Judul & Persentase \\
\hline 1. & 2017 & 185 & $54,7 \%$ \\
\hline 2. & 2018 & 153 & $45,3 \%$ \\
\hline \multicolumn{2}{|c|}{ Jumlah } & 338 & 100 \\
\hline
\end{tabular}

Pada penelitian ini penulis menggunakan model pemetaan Hawkins, yaitu menganalisis bidang kajian ilmu pada setiap judul skripsi yang ditulis oleh Mahasiswa PGSD Universitan Negeri Makassar, tabel ditampilkan di bawah ini:

Tabel 2. Pemetaan Tema Pokok Skripsi Mahasiswa PGSD

\begin{tabular}{|c|l|c|c|c|c|}
\hline \multirow{2}{*}{ No } & \multicolumn{1}{|c|}{ Topic utama } & \multicolumn{2}{|c|}{ Tahun } & Jml & Persentase \\
\cline { 3 - 4 } & & $\mathbf{2 0 1 7}$ & $\mathbf{2 0 1 8}$ & $\mathbf{( F )}$ & \\
\hline 1. & Metode Pembelajaran & 127 & 71 & 198 & $58,58 \%$ \\
\hline 2. & Model Pembelajaran & 30 & 38 & 68 & $18,83 \%$ \\
\hline 3. & Strategi Pembelajaran & 10 & 17 & 27 & $8 \%$ \\
\hline 4. & Pendekatan Pembelajaran & 8 & 8 & 16 & $4,73 \%$ \\
\hline 5. & Topik Lain & 10 & 23 & 33 & $9,76 \%$ \\
\hline & Total & 185 & 153 & 338 & 100 \\
\hline
\end{tabular}

Dari tabel di atas terlihat jelas dari 338 judul skripsi yang dijadikan sampel, pada umumnya mahasiswa Jurusan PGSD Universitas Negeri Makassar bertemakan tentang Metode Pembelajaran (198 judul) dengan persentase 58,58\%. Selanjutnya diikut oleh Model Pembelajaran (68 judul) dengan persentase 18,83\%, Strategi Pembelajaran (27 judul) dengan persentase 8\%, Pendekatan Pembelajaran (16 judul) dengan persentase 4,73\%. Adapun selebihnya topik lain (33 judul) dengan persentase $9,76 \%$.

Tabel di bawah menunjukkan subjek Mata Pelajaran pada sampel skrispi Jurusan PGSD terbit 2017-2018.

Tabel 3. Judul Skripsi Berdasarkan Mata Pelajaran

\begin{tabular}{|c|l|c|c|c|c|}
\hline \multirow{2}{*}{ No } & \multirow{2}{*}{ Mata Pelajaran } & \multicolumn{2}{|c|}{ Tahun } & Jumlah & Persentase \\
\cline { 3 - 5 } & & $\mathbf{2 0 1 7}$ & $\mathbf{2 0 1 8}$ & $\mathbf{( F )}$ & \\
\hline 1. & IPS & 35 & 24 & 59 & $17,46 \%$ \\
\hline 2. & IPA & 70 & 44 & 114 & $33,73 \%$ \\
\hline 3. & PKN & 10 & 7 & 17 & $5,03 \%$ \\
\hline 4. & Matematika & 27 & 40 & 67 & $19,82 \%$ \\
\hline 5. & Bhs.Indonesia & 15 & 10 & 25 & $7,4 \%$ \\
\hline 6. & SBK & 9 & 2 & 11 & $3,25 \%$ \\
\hline 7. & Pokok Bahasan Lain & 19 & 26 & 45 & $13,31 \%$ \\
\hline \multicolumn{2}{r}{ Jumlah } & 185 & 153 & 338 & 100 \\
\hline
\end{tabular}




\section{Diskusi dan Kesimpulan}

Pada umumnya, dari keseluruhan sampel yang diambil, tema atau subjek yang sering dijadikan sebagai penelitian mahasiswa Jurusan PGSD Fakultas Ilmu Pendidikan Universitas Negeri Makassar ada lima, yaitu metode pembelajaran, model pembelajaran, strategi pembelajaran, pendekatan pembelajaran dan tema atau subjek lainnya. Ini hanya berlaku untuk sampel penelitian saja.

Tema yang sering dijadikan subjek penelitian oleh mahasiswa jurusan PGSD Fakultas Ilmu Pendidikan Universitas Negeri Makassar yaitu subjek penelitian di bidang kajian metode pembelajaran sebanyak 198 judul skripsi dengan tingkat persentase sebesar 58,58\%, bidang kajian model pembelajaran sebesar 18,83\%, bidang kajian strategi pembelajaran sebesar $8 \%$, bidang kajian pendekatan pembelajaran sebesar 4,73\% dan bidang kajian lainnya sebesar 9,76\%. Sedangkan mata pelajaran yang sering di teliti yaitu mata pelajaran IPA sebanyak 114 kali dengan persentase sebesar 33,73\%, mata pelajaran IPS sebesar 17,46\%, mata pelajaran Matematika sebesar 19,82\%, mata pelajaran PKN sebesar 5,03\%, mata pelajaran Bhs.Indonesia sebesar 7,4\%, mata pelajaran SBK sebesar 3,25\% dan pokok bahasan lainnya sebesar $13,31 \%$.

Dari hasil ini, Jurusan PGSD dapat melihat arah perkembangan tema penelitian yang telah dihasilkan oleh mahasiswanya. Selain itu, jurusan ini juga dapat mengembangkan tema-tema riset lainnya yang dapat dikaji oleh mahasiswa. Sementara, dari perpustakaan, bahan-bahan bacaan atau literatur dapat disediakan guna mendukung riset-riset yang hendak dilakukan oleh mahasiswa Jurusan PGSD Universitas Negeri Makassar.

\section{Ucapan Terima Kasih}

Peneliti mengucapkan banyak terima kasih kepada Jurusan PGSD UNM dan juga Perpustakaan PGSD UNM yang telah berkenan memberikan kesempatan untuk meneliti skrispi yang dimilikinya. 


\section{Referensi}

Archambault, E., \& Gagne, E. V. (2004). The Use of Bibliomterics in The Social Science and Humanities. Final Report.

Krejcie, R.V. and Morgan, D.W. (1970). Determining sample size for research activities. Educational and Psychological Measurement, 30: 607-610.

Sulistyo-Basuki. (2002). Bibliometrics Sciontometrics dan Infometrics, Kumpulan Makalah Kursus Bibliometrika. Jakarta: Masyarakat Informatika Indonesia.

Diodato. (1994). Dictonary Of Bibliometric. New York: Haworth Press.

Esshra. (2007). Webometrics, Infometrics And Bibliomterics-How Useful Are These Indicators For Measuring Knowledge." A. 7.

Fattah, S. H. (2013). Pemanfaatan Kajian Bibliometrik Sebagai Metode Evaluasi dan Kajian Dalam Ilmu Perpustakaan dan Informasi. Khizanah Al-Hikmah : Jurnal Ilmu Perpustakaan, Informasi, dan Kearsipan. 1(1).

Nelisa, M. (2009). "Pola Produktivitas Pengarang Artikel Bidang Ilmu Perpustakaan dan Informasi di Indonesia Tahun 1978-2007 Analisis Bibliometrika Menggunakan Hukum Lotka.r' Tesis. Jakar'ta: Program Magister Ilmu Perpustakaan FIB UI.

Saleh, R. S. (2017). Studi Bibliometrik dan Sebaran Topik Penelitian Pada Jurnal Hayati Terbitan 2012-2016 Perpustakaan Institut Pertanian Bogor. Jurnal Hayati, Vol 9 No. 2.

Sugiyono. (2013). Metode Penelitian Kuantitatif dan Kualitatif dan R\&D. Jakarta: Alfabet. 